\title{
Short communication: Validation of 4 candidate causative trait variants in 2 cattle breeds using targeted sequence imputation
}

\author{
Hubert Pausch, ${ }^{* 1}$ Christine Wurmser, ${ }^{*}$ Friedrich Reinhardt, $†$ Reiner Emmerling, $\ddagger$ and Ruedi Fries* \\ ${ }^{*}$ Chair of Animal Breeding, Technische Universität München, 85354 Freising, Germany \\ †Vereinigte Informationssysteme Tierhaltung w.V. (VIT), 27283 Verden, Germany \\ IInstitute of Animal Breeding, Bavarian State Research Centre for Agriculture, 85586 Poing, Germany
}

\section{ABSTRACT}

Most association studies for pinpointing trait-associated variants are performed within breed. The availability of sequence data from key ancestors of several cattle breeds now enables immediate assessment of the frequency of trait-associated variants in populations different from the mapping population and their imputation into large validation populations. The objective of this study was to validate the effects of 4 putatively causative variants on milk production traits, male fertility, and stature in German Fleckvieh and HolsteinFriesian animals using targeted sequence imputation. We used whole-genome sequence data of 456 animals to impute 4 missense mutations in DGAT1, GHR, PRLR, and PROP1 into 10,363 Fleckvieh and 8,812 Holstein animals. The accuracy of the imputed genotypes exceeded $95 \%$ for all variants. Association testing with imputed variants revealed consistent antagonistic effects of the DGAT1 p.A232K and GHR p.F279Y variants on milk yield and protein and fat contents, respectively, in both breeds. The allele frequency of both polymorphisms has changed considerably in the past 20 $y r$, indicating that they were targets of recent selection for milk production traits. The $P R L R$ p.S18N variant was associated with yield traits in Fleckvieh but not in Holstein, suggesting that it may be in linkage disequilibrium with a mutation affecting yield traits rather than being causal. The reported effects of the PROP1 p.H173R variant on milk production, male fertility, and stature could not be confirmed. Our results demonstrate that population-wide imputation of candidate causal variants from sequence data is feasible, enabling their rapid validation in large independent populations. Key words: sequence imputation, causal variant, QTN, validation

Received January 30, 2015.

Accepted March 13, 2015.

${ }^{1}$ Corresponding author: hubert.pausch@tierzucht.tum.de

\section{Short Communication}

The availability of dense genotyping arrays facilitates the identification of trait-associated regions using genome-wide association studies (GWAS). Such studies in livestock populations have been particularly successful in mapping causal trait variants for monogenic traits (Nicholas and Hobbs, 2014). Array-based GWAS have also uncovered numerous QTL for complex phenotypes. However, the high extent of linkage disequilibrium in livestock populations typically results in large QTL intervals and renders the identification of causative variants a difficult task. Furthermore, current genotyping arrays in cattle interrogate genotypes for a limited number of polymorphic sites only and most of them are located in noncoding elements of the genome (Koufariotis et al., 2014). Across-breed association studies with imputed sequence variants offer a new and powerful approach to fine-map QTL regions at maximum resolution and to pinpoint the most likely candidate causal variants (Daetwyler et al., 2014).

The consideration of functional variants in genomeassisted breeding programs allows for a more accurate phenotype prediction (Erbe et al., 2012). Obtaining genotypes for a set of well-characterized functional variants might be particularly useful for marker-assisted selection in small populations with an insufficient number of reference animals precluding genomic prediction (Kashi et al., 1990; Meuwissen et al., 2001). However, the validation of trait-associated variants in large independent populations is indispensable, before their information can be used for breeding decisions.

Whole-genome sequencing of key ancestors provides a catalog of annotated variants segregating within and across cattle populations (Jansen et al., 2013; Daetwyler et al., 2014). The sequence-derived genotypes enable rapid assessment of the frequency of trait-associated variants in populations different from the mapping population. Furthermore, the sequence-derived genotypes can be used as a reference to extrapolate genotypes for animals genotyped at lower density (Pausch et al., 2013). The effect of putatively causative variants 
can then be scrutinized in large validation populations. Large samples are particularly important for validating variants that explain a small fraction of the trait variation only (Wray et al., 2013). Consistency of allele substitution effects between mapping and validation populations is required but not sufficient for providing causality. Only functional investigations will ultimately unravel whether a variant is indeed causal or whether the estimated effects result from high linkage disequilibrium with the causative mutation(s) (Kichaev et al., 2014).

Analysis of whole-genome sequencing data revealed 3 putatively causative variants controlling milk production traits to segregate in German Fleckvieh (FV) and Holstein-Friesian (HF) cattle. These variants are missense mutations in GHR (p.F279Y) and PRLR (p.S18N) that were initially identified in HF (Blott et al., 2003) and Finnish Ayrshire cattle (Viitala et al., 2006), respectively, and a missense mutation in DGAT1 (p.A232K) identified in several cattle breeds including FV and HF (Grisart et al., 2002; Winter et al., 2002). Another missense mutation in PROP1 (p.H173R) affecting sire conception rate, milk composition, and longevity in US Holsteins (Lan et al., 2013), as well as growth-related traits in indigenous Chinese cattle breeds (Pan et al., 2013), occurs at high frequency (0.42) in German FV cattle (Table 1). However, GWAS in FV did not uncover QTL for male reproductive performance and growth-related traits in the region of PROP1 (Pausch et al., 2011, 2014a).

To obtain genotypes for the 4 variants in a large number of German FV and HF animals, we performed targeted sequence imputation. The animals of the target populations were genotyped with the IlluminaSNP50 BeadChip and the Illumina BovineHD BeadChip (Illumina Inc., San Diego, CA) comprising 54,609 and 777,962 genome-wide distributed SNP, respectively. Standard quality controls were applied and genotype imputation was performed to extrapolate the medium-density genotypes to higher density, as detailed in Pausch et al. (2014a). After imputation, the target populations consisted of $10,363 \mathrm{FV}$ and 8,812 HF animals, with (partially imputed) genotypes at 635,224 and 587,412 genome-wide distributed SNP, respectively. Because none of the 4 candidate causative trait variants was among the array-derived genotypes, we used sequence data of 145 FV (Pausch et al., 2014b) and 311 Holstein animals from Run4 of the "1000 Bull Genomes" project (Daetwyler et al., 2014) as a reference to impute them into the target populations. Regions for targeted sequence imputation encompassed the $2.5-\mathrm{Mb}$ flanking sequence on either side of the 4 candidate causal variants. The number of array-derived and sequence-derived variants in the 4 target regions ranged from 705 to 1,368 and from 33,273 to 62,126 , with an average of 1,086 and 46,374 variants per target region, respectively. Targeted sequence imputation was performed using a combination of Beagle (Browning and Browning, 2009) and Minimac (Howie et al., 2012), as detailed in Pausch et al. (2014b). To assess the imputation accuracy of the 4 variants, we additionally obtained genotypes using TaqMan (Life Technologies, Carlsbad, CA) and KASP (LGC Genomics, Teddington, UK) genotyping assays. The concordance between the directly obtained and imputed genotypes ranged from 95.70 to $99.50 \%$ (Supplemental Table S1; http:// dx.doi.org/10.3168/jds.2015-9402). Assuming HardyWeinberg equilibrium, the observed genotype distribution did not deviate from the expected $(P>0.11)$.

Response variables for association testing were daughter yield deviations for milk yield (MY), fat yield (FY), and protein yield (PY), as well as EBV for fat percentage (FP) and protein percentage (PP). The fertility of FV and HF bulls was analyzed based on male reproductive ability (MRA) and sire conception rate (SCR), respectively (Fürst and Gredler, 2009; Norman et al., 2011). Bulls with fewer than 100 services were excluded from further analyses, as were FV bulls that were homozygous for a recessive allele that causes subfertility (Pausch et al., 2014a). For stature, we used daughter yield deviations for the FV bulls and EBV for the HF bulls. The number of animals used for associa-

Table 1. Four putatively causative variants segregating in German Fleckvieh (FV) and Holstein (HF) cattle ${ }^{1}$

\begin{tabular}{|c|c|c|c|c|c|c|c|c|}
\hline PROP1 & 7 & $41,208,950$ & rs136195618 & A & $\mathrm{G}$ & p.H173R & $0.42(0.42)$ & $0.09(0.06)$ \\
\hline GHR & 20 & $31,909,478$ & rs385640152 & $\mathrm{T}$ & $\mathrm{A}$ & p.F279Y & $0.07(0.07)$ & $0.16(0.15)$ \\
\hline$P R L R$ & 20 & $39,115,344-39,115,345$ & rs136247583 & GT & $\mathrm{AC}$ & p.S18N & $0.24(0.25)$ & $0.80(0.87)$ \\
\hline
\end{tabular}

${ }^{1}$ The positions and reference alleles (Ref) of 4 putatively causative variants relate to the UMD3.1 assembly of the bovine genome. The frequency $(\mathrm{Fq})$ of the alternative variant (Alt) was obtained based on sequence data of 145 Fleckvieh $\left(\mathrm{Fq}_{\mathrm{FV}}\right)$ and 311 Holstein (F $\left.\mathrm{F}_{\mathrm{HF}}\right)$ animals. Values in parentheses correspond to allele frequencies observed after imputation into 10,363 FV and 8,812 $\mathrm{HF}$ animals, respectively.

${ }^{2}$ National Center for Biotechnology Information database (http://www.ncbi.nlm.nih.gov/SNP/). 


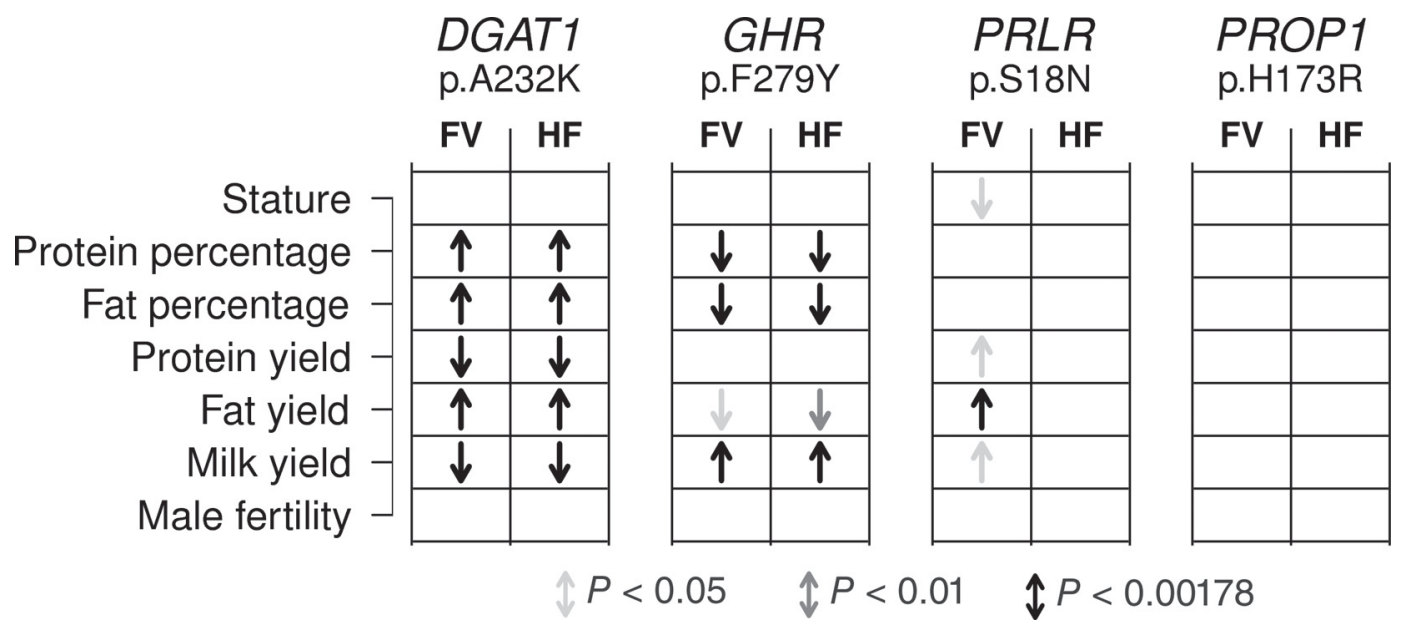

Figure 1. Effect of 4 candidate causal variants on 7 traits in German Fleckvieh and Holstein-Friesian cattle. The arrows indicate significant $(P<0.05)$ genotype $\times$ phenotype associations in Fleckvieh $(\mathrm{FV})$ and Holstein-Friesian $(\mathrm{HF})$ bulls. The up and down arrows indicate positive and negative substitution effects of the alternative variant, respectively. Shades of gray denote different significance thresholds. Black arrows indicate associations that met the Bonferroni-corrected significance threshold. The sample size, allele substitution effects, and corresponding standard errors and $P$-values are detailed in Supplemental Table S2 (http://dx.doi.org/10.3168/jds.2015-9402).

tion testing ranged from 3,390 to 8,803 (Supplemental Table S2; http://dx.doi.org/10.3168/jds.2015-9402).

The 4 variants were tested for association with each trait using a 2-step variance components-based approach to account for population stratification implemented in the EMMAX software tool (Kang et al., 2010). In a first step, the polygenic and error variances were estimated using following variance component model: $\mathbf{y}=\mu+\mathbf{g}+\mathbf{e}$, where $\operatorname{Var}(y)=\mathbf{G} \sigma_{a}^{2}+\mathbf{I} \sigma_{e}^{2}, \mu$ is the intercept, $\mathbf{y}$ is a vector of phenotypes, $\mathbf{G}$ is the genomic relationship matrix built based on genotypes of 635,224 (FV) and 587,412 (HF) autosomal SNP obtained from genotyping with high-density arrays, and $\mathbf{e}$ is a vector of random residual deviates (VanRaden, 2008), $\mathbf{I}$ is an identity matrix, $\sigma_{a}^{2}$ is the additive genetic variance, and $\sigma_{e}^{2}$ is the error variance. In a second step, the SNP effect was obtained using a generalized linear regression model: $\mathbf{y}=\mu+\mathbf{X b}+\mathbf{e}$, where $\mathbf{X}$ is a vector of imputed genotypes (coded as $0,1,2$ ), and $\mathbf{e}$ is a vector of random residual deviates with variance $\mathbf{G} \sigma_{a}^{2}+\mathbf{I} \sigma_{e}^{2}$. Assuming 28 independent tests per breed (association testing of 4 variants with 7 traits), the Bonferroni-corrected significance threshold was $1.78 \times$ $10^{-3}$.

The p.A232K variant in $D G A T 1$ was associated with all milk production traits analyzed $\left(P_{\mathrm{HF}}<1.32 \times 10^{-48}\right.$; $\left.P_{\mathrm{FV}}<4.91 \times 10^{-4}\right)$ and it explained 30.01 and $35.65 \%$ of the FP variation in FV and $\mathrm{HF}$, respectively (Figure 1, Supplemental Table S2; http://dx.doi.org/10.3168/ jds.2015-9402). The lysine variant decreased MY and $\mathrm{PY}$ and enhanced FY, FP, and PP. In the past $20 \mathrm{yr}$, the frequency of the lysine-encoding allele of $0.08 \mathrm{did}$ not change in $\mathrm{FV}(P=0.42)$. However, its frequency decreased from 0.45 (birth years 1986 to 1990) to 0.24 (2004 to 2008$)$ in $\operatorname{HF}\left(P=3.01 \times 10^{-7}\right.$, Supplemental Figure S1; http://dx.doi.org/10.3168/jds.2015-9402).

The p.F279Y variant in $G H R$ was associated with MY, FY, FP, and PP in both breeds, with PP being the most strongly affected trait (Figure 1, Supplemental Table S2). In FV and HF, the p.F279Y variant explained 1.3 and $6.17 \%$ of the $\mathrm{PP}$ variation, respectively. The frequency of the tyrosine variant (i.e., MYenhancing and milk contents-lowering) decreased in both populations $\left(P_{\mathrm{FV}}=0.0045, P_{\mathrm{HF}}=0.0012\right.$, Supplemental Figure S1).

The p.S18N variant in $P R L R$ affected MY, FY, PY, and stature in $\mathrm{FV}(P<0.05)$ and explained from 0.14 to $0.23 \%$ of the respective trait variation. However, only FY remained significantly associated after correcting for multiple testing (Figure 1, Supplemental Table S2; http://dx.doi.org/10.3168/jds.2015-9402). The asparagine variant enhanced FY. Its frequency is slightly decreasing in FV $(P=0.0127$, Supplemental Figure S1). In German HF, none of the traits analyzed showed association with the p.S18N variant $(P>0.25)$.

The p.H173R variant in PROP1 did not show association with milk production traits, male fertility, or stature (Figure 1, Supplemental Table S2; http:// dx.doi.org/10.3168/jds.2015-9402). In 10,363 and 8,812 animals of the FV and HF populations, the frequency of the arginine-encoding allele was 0.42 and 0.06 (Table 1 ), respectively, and it did not change in the past 20 yr $\left(P_{\mathrm{FV}}=0.15, P_{\mathrm{HF}}=0.07\right.$, Supplemental Figure S1).

Our study was based on imputed sequence-derived genotypes for 4 candidate causal polymorphisms in 8,812 HF and 10,363 FV animals. The reference popu- 
lation for imputation consisted of a small number of sequenced key ancestors of both breeds. Genotype imputation based on a small reference population may be inaccurate, particularly for low-frequency variants (Pausch et al., 2013), and using genotypes with poor imputation quality in validation studies may significantly distort the estimates of marker effects (Ertl et al., 2014). In the present study, the concordance between imputed and true genotypes exceeded $95 \%$ for all 4 candidate causal variants. Thus, it is unlikely that the observed allele substitution effects were notably biased by imputation errors.

Imputation and validation of the DGAT1 p.A232K variant can be considered as a proof of concept, because its effects on milk production traits have been documented in several cattle breeds including FV and HF. Our estimates of the allele substitution effects based on imputed genotypes were in good agreement with those from previous studies using direct genotyping (e.g., Winter et al., 2002; Grisart et al., 2002; Thaller et al., 2003a; Berry et al., 2010). Different allele substitution effects across populations are mainly attributable to unequal allele frequencies and different sample sizes. The frequency of the lysine variant decreased considerably in the German HF population, indicating that the recent increase in milk yield in Holstein cattle is partly attributable to selection of animals carrying the alanine variant, which enhances milk yield. However, the favorable effect of the lysine variant on the deposition of intramuscular fat (Thaller et al., 2003b), its low frequency, and less intense selection on milk production traits in dual-purpose breeds might explain the constant frequency in FV.

Our results confirmed that the GHR $279 \mathrm{Y}$ variant enhances milk yield and lowers milk content in $\mathrm{HF}$ (e.g., Blott et al., 2003; Rahmatalla et al., 2011). Additionally, we provide evidence that the p.F279Y variant similarly affects milk production traits in FV, corroborating its presumed causal role. The p.F279Y variant has likely been a target of recent selection for protein content because the frequency of the PP-enhancing (i.e., phenylalanine-encoding) allele increased in both $\mathrm{FV}$ and $\mathrm{HF}$, which agrees with selection signature analyses in several cattle breeds (Hayes et al., 2009; Rothammer et al., 2013).

The association study with the $P R L R$ p.S18N variant yielded deviating results in FV and $\mathrm{HF}$. In FV, the asparagine variant enhanced FY, which agrees with findings in Finnish Ayrshire (Viitala et al., 2006). However, the p.S18N variant was not associated with milk production traits in the German HF population, which agrees with the results of Blott et al. (2003) and Wang et al. (2012). The p.S18N variant in PRLR might be in linkage disequilibrium with a mutation affecting yield traits, rather than being causative itself, and the inconsistent allele substitution effects might result from varying linkage phases.

Our findings regarding the PROP1 p.H173R variant in the German HF population disagree in many respects with those reported for the US Holstein population. Lan et al. (2013) obtained genotypes for the p.H173R variant in 255 US Holsteins and imputed them into 1,696 animals genotyped with the Illumina BovineSNP50 BeadChip. They report deviation from the Hardy-Weinberg equilibrium of the imputed genotypes as well as antagonistic effects of the p.H173R variant on SCR and milk production traits. Our study based on 8,812 animals of the German HF population did not show deviation from the Hardy-Weinberg equilibrium $(P=0.48)$, and the p.H173R variant in PROP1 was not associated with SCR $(P=0.68)$ or with milk production traits $(P>0.24)$, although the frequency of the arginine-encoding allele was similar to that observed in the US Holstein population. The p.H173R variant showed no association with MRA or milk production traits in FV. It is unlikely that the lack of association is a false-negative result caused by incorrectly imputed genotypes because the imputation accuracy was very high in both breeds (>98.18\%). Furthermore, the number of genotyped animals was twice (HF) and 4 times $(\mathrm{FV})$ the number of animals genotyped in the study of Lan et al. (2013). Thus, the present study would have had enough power to replicate true effects. It seems likely that Lan et al. (2013) overestimated the effect of the p.H173R variant due to a small sample size and imperfect imputation, respectively.

Association of the PROP1 p.H173R variant with growth-related traits was reported in small samples $(160<\mathrm{n}<405)$ of indigenous Chinese cattle breeds (Pan et al., 2013). However, the association analysis was carried out without properly accounting for the relationship among the genotyped animals. Not considering population stratification in GWAS may cause an inflation of spurious associations (Price et al., 2006; Pausch et al., 2011). Our association study considered population stratification by accounting for the genomic relationship estimated based on genome-wide marker data. In the present study, the p.H173R variant was not associated with stature in more than 15 (FV) and 20 (HF) times the number of animals compared with the study of Pan et al. (2013).

Taken together, our findings do not support that the p.H173R variant in PROP1 affects milk production, male fertility, or stature in cattle. If the polymorphism affects these phenotypes at all, its effect must be very small; otherwise, it should have been detected in the present study because we were able to replicate effects for variants that explain less than $0.5 \%$ of the 
trait variation. Using the $P R O P 1$ p.H173R variant in genome-assisted selection programs, as recommended by Lan et al. (2013) and Pan et al. (2013), is thus not likely to improve milk production, male fertility, or growth-related traits in cattle.

Sequence-based association studies will reveal numerous trait-associated variants for important traits in several cattle breeds. However, GWAS with imputed sequence variants usually yield many highly significantly associated variants in close linkage disequilibrium, rendering the identification of causal variants a difficult task (Daetwyler et al., 2014; Sahana et al., 2014). Using the approach of the present study; that is, assessing the frequency of trait-associated variants in independent populations and their imputation into large validation populations followed by association testing, will allow a considerable reduction in the number of candidate causal variants for QTL regions. However, surveying the imputation accuracy for potentially causative variants is crucial, particularly when the number of sequenced reference animals is low.

\section{ACKNOWLEDGMENTS}

The sequencing of Fleckvieh bulls was funded by the German Federal Ministry of Education and Research (Bonn, Germany) within the AgroClustEr "Synbreed - Synergistic plant and animal breeding" (grant nos. 0315527B, 0315528A). We thank the Förderverein für Biotechnologieforschung e.V. (Bonn, Germany) for financial support and the 1000 Bull Genomes Project (Melbourne, Australia) for sharing whole-genome sequence data of Holstein animals. The authors acknowledge the German Holstein Association (Bonn, Germany), the Confederación de Asociaciones de Frisona Española (Valdemoro, Spain), the Arbeitsgemeinschaft Süddeutscher Rinderzüchter e.V. (München, Germany), the Arbeitsgemeinschaft österreichischer Fleckviehzüchter (Zwettl, Austria), and ZuchtData EDV Dienstleistungen GmbH (Wien, Austria) for providing genotype data.

\section{REFERENCES}

Berry, D. P., D. Howard, S. O'Boyle, S. Waters, J. F. Kearney, and M. McCabe. 2010. Associations between the K232A polymorphism in the diacylglycerol-O-transferase 1 (DGAT1) gene and performance in Irish Holstein-Friesian dairy cattle. Ir. J. Agric. Food Res. 49:1-9.

Blott, S., J.-J. Kim, S. Moisio, A. Schmidt-Küntzel, A. Cornet, P. Berzi, N. Cambisano, C. Ford, B. Grisart, D. Johnson, L. Karim, P. Simon, R. Snell, R. Spelman, J. Wong, J. Vilkki, M. Georges, F. Farnir, and W. Coppieters. 2003. Molecular dissection of a quantitative trait locus: A phenylalanine-to-tyrosine substitution in the transmembrane domain of the bovine growth hormone receptor is associated with a major effect on milk yield and composition. Genetics 163:253-266.
Browning, B. L., and S. R. Browning. 2009. A unified approach to genotype imputation and haplotype-phase inference for large data sets of trios and unrelated individuals. Am. J. Hum. Genet. 84:210-223. http://dx.doi.org/10.1016/j.ajhg.2009.01.005.

Daetwyler, H. D., A. Capitan, H. Pausch, P. Stothard, R. van Binsbergen, R. F. Brøndum, X. Liao, A. Djari, S. C. Rodriguez, C. Grohs, D. Esquerré, O. Bouchez, M.-N. Rossignol, C. Klopp, D. Rocha, S. Fritz, A. Eggen, P. J. Bowman, D. Coote, A. J. Chamberlain, C. Anderson, C. P. VanTassell, I. Hulsegge, M. E. Goddard, B. Guldbrandtsen, M. S. Lund, R. F. Veerkamp, D. A. Boichard, R. Fries, and B. J. Hayes. 2014. Whole-genome sequencing of 234 bulls facilitates mapping of monogenic and complex traits in cattle. Nat. Genet. 46:858-865. http://dx.doi.org/10.1038/ng.3034.

Erbe, M., B. J. Hayes, L. K. Matukumalli, S. Goswami, P. J. Bowman, C. M. Reich, B. A. Mason, and M. E. Goddard. 2012. Improving accuracy of genomic predictions within and between dairy cattle breeds with imputed high-density single nucleotide polymorphism panels. J. Dairy Sci. 95:4114-4129. http://dx.doi.org/10.3168/ jds.2011-5019.

Ertl, J., C. Edel, R. Emmerling, H. Pausch, R. Fries, and K.-U. Götz. 2014. On the limited increase in validation reliability using highdensity genotypes in genomic best linear unbiased prediction: Observations from Fleckvieh cattle. J. Dairy Sci. 97:487-496. http://dx.doi.org/10.3168/jds.2013-6855.

Fürst, C., and B. Gredler. 2009. Genetic evaluation for fertility traits in Austria and Germany. Interbull Bull. 40:3-9.

Grisart, B., W. Coppieters, F. Farnir, L. Karim, C. Ford, P. Berzi, N. Cambisano, M. Mni, S. Reid, P. Simon, R. Spelman, M. Georges, and R. Snell. 2002. Positional candidate cloning of a QTL in dairy cattle: Identification of a missense mutation in the bovine DGAT1 gene with major effect on milk yield and composition. Genome Res. 12:222-231. http://dx.doi.org/10.1101/gr.224202.

Hayes, B. J., A. J. Chamberlain, S. Maceachern, K. Savin, H. McPartlan, I. MacLeod, L. Sethuraman, and M. E. Goddard. 2009. A genome map of divergent artificial selection between Bos taurus dairy cattle and Bos taurus beef cattle. Anim. Genet. 40:176-184. http://dx.doi.org/10.1111/j.1365-2052.2008.01815.x.

Howie, B., C. Fuchsberger, M. Stephens, J. Marchini, and G. R. Abecasis. 2012. Fast and accurate genotype imputation in genome-wide association studies through pre-phasing. Nat. Genet. 44:955-959. http://dx.doi.org/10.1038/ng.2354.

Jansen, S., B. Aigner, H. Pausch, M. Wysocki, S. Eck, A. Benet-Pagès, E. Graf, T. Wieland, T. M. Strom, T. Meitinger, and R. Fries. 2013. Assessment of the genomic variation in a cattle population by re-sequencing of key animals at low to medium coverage. BMC Genomics 14:446 http://dx.doi.org/10.1186/1471-2164-14-446.

Kang, H. M., J. H. Sul, S. K. Service, N. A. Zaitlen, S. Kong, N. B. Freimer, C. Sabatti, and E. Eskin. 2010. Variance component model to account for sample structure in genome-wide association studies. Nat. Genet. 42:348-354. http://dx.doi.org/10.1038/ ng.548.

Kashi, Y., E. Hallerman, and M. Soller. 1990. Marker-assisted selection of candidate bulls for progeny testing programmes. Anim. Prod. 51:63-74. http://dx.doi.org/10.1017/S0003356100005158.

Kichaev, G., W.-Y. Yang, S. Lindstrom, F. Hormozdiari, E. Eskin, A. L. Price, P. Kraft, and B. Pasaniuc. 2014. Integrating functional data to prioritize causal variants in statistical fine-mapping studies. PLoS Genet. 10:e1004722 http://dx.doi.org/10.1371/journal. pgen.1004722.

Koufariotis, L., Y.-P. P. Chen, S. Bolormaa, and B. J. Hayes. 2014. Regulatory and coding genome regions are enriched for trait-associated variants in dairy and beef cattle. BMC Genomics 15:436 http://dx.doi.org/10.1186/1471-2164-15-436.

Lan, X. Y., F. Peñagaricano, L. Dejung, K. A. Weigel, and H. Khatib. 2013. Short communication: A missense mutation in the PROP1 (prophet of Pit 1) gene affects male fertility and milk production traits in the US Holstein population. J. Dairy Sci. 96:1255-1257. http://dx.doi.org/10.3168/jds.2012-6019.

Meuwissen, T. H., B. J. Hayes, and M. E. Goddard. 2001. Prediction of total genetic value using genome-wide dense marker maps. Genetics $157: 1819-1829$. 
Nicholas, F. W., and M. Hobbs. 2014. Mutation discovery for Mendelian traits in non-laboratory animals: A review of achievements up to 2012. Anim. Genet. 45:157-170. http://dx.doi.org/10.1111/ age. 12103 .

Norman, H. D., J. L. Hutchison, and P. M. VanRaden. 2011. Evaluations for service-sire conception rate for heifer and cow inseminations with conventional and sexed semen. J. Dairy Sci. 94:61356142. http://dx.doi.org/10.3168/jds.2010-3875.

Pan, C., C. Wu, W. Jia, Y. Xu, C. Lei, S. Hu, X. Lan, and H. Chen. 2013. A critical functional missense mutation (H173R) in the bovine PROP1 gene significantly affects growth traits in cattle. Gene 531:398-402. http://dx.doi.org/10.1016/j.gene.2013.09.002.

Pausch, H., B. Aigner, R. Emmerling, C. Edel, K.-U. Götz, and R Fries. 2013. Imputation of high-density genotypes in the Fleckvieh cattle population. Genet. Sel. Evol. 45:3 http://dx.doi. org/10.1186/1297-9686-45-3.

Pausch, H., K. Flisikowski, S. Jung, R. Emmerling, C. Edel, K.-U. Götz, and R. Fries. 2011. Genome-wide association study identifies two major loci affecting calving ease and growth-related traits in cattle. Genetics 187:289-297. http://dx.doi.org/10.1534/ genetics.110.124057.

Pausch, H., S. Kölle, C. Wurmser, H. Schwarzenbacher, R. Emmerling, S. Jansen, M. Trottmann, C. Fuerst, K.-U. Götz, and R. Fries. 2014a. A nonsense mutation in TMEM95 encoding a nondescript transmembrane protein causes idiopathic male subfertility in cattle. PLoS Genet. 10:e1004044 http://dx.doi.org/10.1371/journal. pgen.1004044.

Pausch, H., C. Wurmser, C. Edel, R. Emmerling, K.-U. Götz, and F. Ruedi. 2014b. Exploiting whole genome sequence data for the identification of causal trait variants in cattle. Proc. 10th World Congr. Genet. Appl. Livest. Prod. (WCGALP), Vancouver, Canada. Accessed Apr. 1, 2015. https://asas.org/docs/default-source/ wcgalp-proceedings-oral/191_paper_10262_manuscript_1271_0. pdf?sfvrsn $=2$

Price, A. L., N. J. Patterson, R. M. Plenge, M. E. Weinblatt, N. A. Shadick, and D. Reich. 2006. Principal components analysis corrects for stratification in genome-wide association studies. Nat. Genet. 38:904-909. http://dx.doi.org/10.1038/ng1847.

Rahmatalla, S. A., U. Müller, E. M. Strucken, M. Reissmann, and G. A. Brockmann. 2011. The F279Y polymorphism of the GHR gene and its relation to milk production and somatic cell score in German Holstein dairy cattle. J. Appl. Genet. 52:459-465. http:// dx.doi.org/10.1007/s13353-011-0051-3.
Rothammer, S., D. Seichter, M. Förster, and I. Medugorac. 2013. A genome-wide scan for signatures of differential artificial selection in ten cattle breeds. BMC Genomics 14:908 http://dx.doi. org/10.1186/1471-2164-14-908.

Sahana, G., B. Guldbrandtsen, B. Thomsen, L.-E. Holm, F. Panitz, R. F. Brøndum, C. Bendixen, and M. S. Lund. 2014. Genomewide association study using high-density single nucleotide polymorphism arrays and whole-genome sequences for clinical mastitis traits in dairy cattle. J. Dairy Sci. 97:7258-7275. http://dx.doi. org/10.3168/jds.2014-8141.

Thaller, G., W. Krämer, A. Winter, B. Kaupe, G. Erhardt, and R. Fries. 2003a. Effects of DGAT1 variants on milk production traits in German cattle breeds. J. Anim. Sci. 81:1911-1918.

Thaller, G., C. Kühn, A. Winter, G. Ewald, O. Bellmann, J. Wegner, H. Zühlke, and R. Fries. 2003b. DGAT1, a new positional and functional candidate gene for intramuscular fat deposition in cattle. Anim. Genet. 34:354-357.

VanRaden, P. M. 2008. Efficient methods to compute genomic predictions. J. Dairy Sci. 91:4414-4423. http://dx.doi.org/10.3168/ jds.2007-0980.

Viitala, S., J. Szyda, S. Blott, N. Schulman, M. Lidauer, A. MäkiTanila, M. Georges, and J. Vilkki. 2006. The role of the bovine growth hormone receptor and prolactin receptor genes in milk, fat and protein production in Finnish Ayrshire dairy cattle. Genetics 173:2151-2164. http://dx.doi.org/10.1534/genetics.105.046730.

Wang, X., C. Wurmser, H. Pausch, S. Jung, F. Reinhardt, J. Tetens, G. Thaller, and R. Fries. 2012. Identification and dissection of four major QTL affecting milk fat content in the German Holstein-Friesian population. PLoS ONE 7:e40711 http://dx.doi.org/10.1371/ journal.pone.0040711.

Winter, A., W. Krämer, F. A. O. Werner, S. Kollers, S. Kata, G. Durstewitz, J. Buitkamp, J. E. Womack, G. Thaller, and R. Fries. 2002. Association of a lysine-232/alanine polymorphism in a bovine gene encoding acyl-CoA:diacylglycerol acyltransferase (DGAT1) with variation at a quantitative trait locus for milk fat content. Proc. Natl. Acad. Sci. USA 99:9300-9305. http://dx.doi. org/10.1073/pnas.142293799.

Wray, N. R., J. Yang, B. J. Hayes, A. L. Price, M. E. Goddard, and P. M. Visscher. 2013. Pitfalls of predicting complex traits from SNPs. Nat. Rev. Genet. 14:507-515. http://dx.doi.org/10.1038/nrg3457. 